\title{
Academic Libraries in the Information Society
}

\author{
Sheila Corrall \\ Director of Library \& Information Services, Aston University, Birmingham.
}

\begin{abstract}
The way that higher education library services are viewed, planned and managed must change radically if they are to survive and thrive in the future. Advances in technology, economic and political pressures, and socio-demographic factors have combined to create an environment posing unprecedented challenges and opportunities. The Joint Funding Councils' Libraries Review has highlighted the need for stronger management and more confident involvement in institutional planning and organizational change. Electronic communication will transform service provision, with significant shifts towards distributed networked services, empowering the end-user and offering new roles and responsibilities to information intermediaries. Effective communication between library, computing and academic staff will be essential to ensure relevant and responsive services. New resource models will be required to take account of diverse customer needs and different modes of delivery. Organizational structures and management styles must change to meet future needs and human resource development must be given higher priority. Bold leadership will enable libraries to enhance their strategic role and respond positively to environmental change.
\end{abstract}

\section{The Virtual Librarian}

The role of the University librarian had changed. Once it had been a stock character part, the very image of scholarly exactitude, ever open to trade influence for tradition, a relic of the institution's past and uninvolved with its future. Now, the reformists' cry of "access not holdings" had worked right through the information chain. Publishers had abandoned their warehouses - they too could adopt just-in-time management: their role was now in packaging, marketing and brokering. The actual storage of knowledge - the articles, texts, interactive experiences - had been passed back to its creators in universities and elsewhere, to be retrieved, reformatted into the house style, and delivered to whoever ordered it. So the Library had gradually picked up both ends of the chain: managing the University's backlist and negotiating its sale and delivery worldwide. At the same time it worked with academic staff in a more traditional function to identify and garner good material from the ends of the earth - and within budget... The University Librarian was now an equal seeker after R\&D money, and his staff's job security depended not on a neverreducing cataloguing backlog but on good project control with results on time [1].

The above scenario, taken from sketches produced by the Information Technology subgroup of the Joint Funding Councils' Libraries Review Group [1] anticipates the changes and challenges facing academic libraries today. The Report of the Review Group, chaired by Professor Sir Brian Follett, predicts fundamental change, but argues that it "will take place gradually, and will need to be managed in conjunction with handling traditional library resources". However, the Follett report leaves us in no doubt that the way higher education library services are viewed, planned and managed must change radically if they are to survive and thrive into the next century, and that urgent action is needed to counter the environmental forces currently threatening their future. The challenge for library managers surely lies in judging the pace of change, striking the right balance and managing the inherent tension between tradition and transformation. Follett 
also points out that such progress will be critically dependent on effective staff development and deployment, and the related report by the John Fielden Consultancy confirms the need for significant improvement in human resource management in academic libraries [2].

\section{Environmental Trends and Developments}

The current pressures and issues affecting library and information services in all sectors are well known and have been documented in numerous articles and reports over the past decade. Of particular relevance in the context of academic and research libraries are the analyses offered by the Follett and Fielden reports, together with the working papers of the IT sub-group [3] and two other seminal reports which also advanced the view that electronic publishing will transform scholarly communication, not only in science, technology and medicine, but also in the humanities $[4,5]$. Technology and economics tend to be seen as the dominant forces driving us towards a world of relentless pressure to do more with less, but political and sociodemographic issues are also having a significant impact on service provision. These factors have been evident for a long time, but the cumulative effect of their combined impact has recently prompted closer scrutiny by government and other funding bodies, as reflected by the Follett review, the comparable review of public libraries initiated by the Department for National Heritage, and ongoing requirements for special libraries to justify their existence to their paymasters. The key trends are common to all types of libraries, but there have been particular developments in higher education over the last decade which have presented additional problems.

\section{Technology advances}

Advances in information and communication technologies have introduced new options for service delivery - notably for self-service and remote access - and raised the expectations of funding bodies and library customers.

Significant areas include:

- local and wide area networking;

- electronic publishing, including multimedia;

- office automation and personal productivity tools;

- new "third generation" library housekeeping systems;

- mass markets for electronic information products and services.

Local and metropolitan area networks linked to national and international networks offer endusers fast online access to information resources from their offices (or homes) including current awareness and document supply via new commercial services, with a choice of delivery modes and payment methods as an alternative to traditional library sources; the progressive expansion and enhancement of SuperJANET (the UK academic network) will also facilitate interlibrary cooperation. The proliferation of electronic information products and services in a multiplicity of formats has made the evaluation and selection of material a more complex business, and also poses questions about the identification and long-term storage of definitive versions of publications. Word-processing, spreadsheets, graphics and desk-top publishing packages have become standard office tools allowing improvements in the efficiency and effectiveness of dayto-day administrative and managerial tasks. The new generation of Unix-based library housekeeping systems running on industry-standard hardware are cheaper to maintain, requiring less staff effort, and offer lots of useful features - such as customized screens, down- 
loading of scanned data, more sophisticated searching, tailored management information reports, and easier links to other internal and external systems and databases. Finally, the growth in CD-ROMs and other electronic products aimed at the consumer market together with mass media interest in the Internet is raising awareness among the general public of the capabilities of information systems which can be expected to stimulate demand among both existing and new customers.

\section{Economic forces}

Continuing global economic and budget pressures have had a disproportionate effect on libraries and information centres as their acquisitions purchasing power has declined against growth in published output.

Key factors include:

- public and private sector financial constraints;

- price inflation for all forms of print publications;

- instability and unpredictability of IT-related costs;

- continuing difficulties over intellectual property rights;

- new entrants in global and more competitive markets.

Budget cuts in both public and private sectors have affected staffing levels and acquisitions expenditure. Staff reductions through "frozen" posts and "natural wastage" have more recently been accelerated by actual redundancies, and there has been an increase lately in the number of appointments offered on fixed-term rather than permanent contracts, notably in the higher education sector. Even where acquisitions spend has been maintained at the same level in cash terms, with book and periodical prices rising at a rate well above general inflation and subject to currency fluctuations, and the number of new titles published worldwide growing each year, the effects have been considerable. Substitution of electronic for printed information resources has provided some respite, but the relative cost-effectiveness of the newer media is difficult to assess when all capital and recurring expenditure is taken into account, and the variety of pricing policies and structures offered by producers and suppliers for standalone and networked products shows continuing uncertainty about their economic viability. Copyright remains a major problem, with publishers attempting to recoup perceived lost sales from photocopying through stringent licensing arrangements and to impose even tighter controls on reproduction of electronic data. With information increasingly being viewed as a tradeable commodity, and technology fostering the development of a more complex global industry, libraries are having to collaborate and compete with information brokers and new entrants to the market, as well as redefining relationships with subscription agents and others taking on new roles in the networked environment.

\section{Political influences}

Government determination to force the public sector to adopt a more competitive and commercial outlook has led to an uneasy blend of marketing principles overlaid with bureaucratic requirements.

Characteristic features include:

- focus on accountability and value for money;

- pressure to move operations into the private sector;

- emphasis on improved quality and choice for the consumer; 
- reluctance to create an effective framework for national co-ordination;

- contradiction between central direction/standards and local autonomy.

As organizations generally have become more accountable to shareholders and funders, library and information services have been subject to similar internal pressures to demonstrate the value added to their parent bodies. Local authority and government libraries have had to cost their services and submit bids for comparison with private-sector operators in the context of compulsory competitive tendering and market testing exercises; higher education libraries have so far escaped this form of evaluation, but many have been subject to formal review by their institutions. The Citizen's Charter and other quality initiatives have reinforced the requirement for accountability, with libraries increasingly being obliged to define their services in terms of quantitative standards, introduce complaints procedures, and publicize details of performance against targets. Although the principle of self-determination of service objectives to meet local community needs has been upheld by national reports and reviews, there is an inherent tension between such utterances and the de facto setting of standards which results from publication of statistics in the form of league tables encouraging comparisons of levels of provision between a library and its peers. A further frustration in the current political environment is the continuing lack of any coherent national information policy initiative for the UK and the failure to use the opportunity of the creation of a new Library and Information Commission to put in place an effective framework for coordination of activities across different sectors.

\section{Socio-demographic factors}

The "post-industrial" or "information" society has been portrayed as a world of knowledge workers and empowered citizens where information assumes much greater importance than before.

Relevant aspects include:

- growth in demand for information;

- changes in employment and working patterns;

- focus on skills training, personal development and life-long learning;

- variety of linguistic and educational backgrounds of information users;

- disparities in information-handling capabilities and experience of library customers.

The continuing worldwide growth in formal and informal publication, development of mass markets for electronic products and services, and pressure for public access to information all point to increasing demands on libraries and other information providers, but from an increasingly disparate client base with distinctive needs. The electronic revolution has the potential to empower some people, while in effect disenfranchising others, and creating an information "underclass" of those who do not have the means of access to computer-mediated information. In the short to medium term, we can expect a wide range of information-handling abilities and aptitudes among users representing different ethnic, educational and economic backgrounds. Predicted shifts in job types and career paths, coupled with a continuing requirement to upgrade knowledge and skills, have implications for library managers both as service providers and as employers.

\section{Higher education developments}

The enlarged higher education sector of the 1990s is under pressure to maintain standards and improve quality, but struggling to articulate a long-term strategy without a secure resource base. 
Current issues include:

- expansion in student numbers;

- changes in teaching and learning patterns;

- different funding arrangements and assumptions;

- focus on quality and efficiency supported by new technologies;

- organizational restructuring, especially convergence of libraries and computer centres.

Higher education has changed from an elite activity to a mass market operation with almost one-in-three school leavers entering the sector in 1995 (compared with one-in-eight in 1980) and a parallel growth in the proportion of entrants without A-levels, older adults, part-time and distance learners, and more students working towards diplomas rather than degrees. There has been a shift in thinking about the nature and purpose of higher education, with more focus on preparation for employment and the development of general conceptual and creative abilities and personal transferable skills, in place of the accumulation of factual information; teaching and learning methods have moved significantly towards individual and group project work and resource-based learning, increasingly with modular course structures. Government financial support per student is being reduced year-on-year as reflected in institutions' funding settlements, tuition fees and student grants; students are being expected to bear more of the cost of their education, and encouraged to view it as a consumer good with themselves as customers. Research funding has become more selective, explicitly linked to external assessment of departments' standing, in effect creating elite groupings and leading to widening disparity in library support. The Higher Education Funding Councils are continuing to push for both gains in efficiency (represented as cost reductions) and improvements in the quality of the student learning experience (evaluated via quality assessment exercises). The Councils see new technology as a potential solution to problems posed by growth, as evidenced by a series of initiatives encouraging application of information technology to benefit the sector as a whole (for example, the Computers in Teaching Initiative and the Teaching and Learning Technology Programme). Organizational structures are being reviewed and remodelled in response to environmental events, including mergers of libraries with computing services and/or other units (such as audiovisual, media and print departments) as well as new internal funding arrangements to reflect the desire for transparency and accountability.

\section{The Follett Report}

The most important recent development for libraries in the higher education sector was the establishment of the Joint Funding Councils' Libraries Review Group in 1992 and the subsequent publication of its report in December 1993. Despite the fanciful scenario presented by the IT sub-group (quoted above), the report is essentially pragmatic in outlook, based on an assessment of trends and developments over the next five to ten years and concentrating on recommendations intended to bring real benefits to the sector. The attention given to the report by the Funding Councils, higher education institutions and the wider library and information world confirms its status as the most significant event for academic libraries since the publication of the Parry report in July 1967 [6]. A critical factor influencing the reception of the report was the substantial sums of money attached to its recommendations - £50 million in earmarked capital grants to provide more space for students and materials, £20 million for an electronic libraries programme of research and demonstration projects, and £10 million as recurrent funding to support specialized research collections of national importance. Continuing interest in the report has been encouraged by significant progress towards implementing 
recommendations since its publication.

Although generally welcomed by the academic library community, not least because it has put the future of library provision firmly on institutional agendas, the report has also been criticized for being bland and conservative. This is partly caused by the Review Group's determination not to suggest a single model or blueprint for the university library of the future, and its conviction that traditional library resources will be supplemented - not suddenly supplanted - by new media. However, the attention given to the potential of information technology to transform library services in support of teaching and research reinforces one of the report's opening statements that "The traditional view of the library as the single repository of information needed for teaching, learning and research is no longer adequate".

The report contains other critical recommendations which have also prompted debate at institutional and national level, notably in respect of the library's involvement in information and institutional management and the development of information strategies. The advantages of organizational and/or operational convergence of libraries and other support services (such as computing and educational technology) are also considered by both Follett and Fielden, but again left as a matter for institutional decision.

It is too early to assess the full impact of the Follett report on future library and information services provision, but already we can point to a promised substantial amount of new and converted space through the capital programme; a programme of several studies and experiments, including electronic journals, document delivery, digitization of journal backruns, integrated bibliographic data-bases, on-demand publishing and subject gateways to improve access to networked resources; the prospect of an IT-related training and awareness initiative to equip library staff with the knowledge, skills and insights to support users in the electronic environment; additional recurrent funding to support humanities collections as a national resource, and a commitment to develop a national/ regional strategy for research support; and a proposed set of generic performance indicators, intended for adoption/adaptation by institutions for the 1995/96 academic year [7]. While the Funding Councils have been quick to respond to the report, with visible results, it is more difficult to predict the outcome of those recommendations directed specifically at institutions - and their libraries. These concentrate on management aspects but cover a broad spectrum of decision making from policy and strategic issues to more tactical matters and operational methods.

Both Follett and Fielden acknowledge wide variations in management practice at present and indicate the need for major improvements in many libraries, particularly in terms of adopting a more strategic approach to the planning and delivery of library and information services, and (especially) to human resource development. These criticisms are fair comment as examination of the strategic plans produced by university libraries shows that most are essentially tactical documents and almost all fail to give the breadth and depth of coverage required to human resource management. The recommendations and comments contained in both reports effectively offer a checklist of areas to be addressed by institutions as they embark on the strategic review suggested as part of the process of formulating an information strategy. Key issues include:

- identifying information needs of various client groups;

- determining the balance between holdings and access;

- achieving co-ordination between library and academic staff;

- clarifying resource allocation and budget distribution mechanisms; 
- specifying performance indicators and quality assurance arrangements;

- improving working practices, especially for "non-professional" staff;

- formulating policies and plans for staff development;

- setting opening hours to optimize space utilization;

- investigating the scope for high-density storage.

\section{Service Implications}

The diversity of the higher education sector of the future and the difficulty of predicting accurately the pace of change makes it hard to arrive at any precise forecast of service developments, but some general trends can be deduced from the environmental influences identified - in particular, the move from holdings to access, the shift from print to electronic media and the development of self-service facilities in a more distributed model of information provision. Customer orientation will be a crucial issue as determining the most cost-effective mix of service provision for each institution will depend on effective liaison and communication between library staff and their clientele. However, it is fairly certain that for the foreseeable future managers will face the challenge of continuing and improving existing offerings at the same time as developing and delivering new services.

There will be huge pressure on study facilities - requiring more reader places and PC facilities, space for silent study and group work, with calls for 24-hour access and wiring of student residences to provide remote access to services, as well as improved links between campus and workplace for part-time and distance learners. We can expect a progressive decline in onsite holdings of printed journals, with development of electronic journals and other modes of formal and informal scholarly communication, resulting in access to a mix of locally mounted and remotely stored full-text and image files, under various licensing arrangements for regular or occasional usage. There will be continuing demand for traditional loan services, especially short-loan collections of recommended student text-books and resource packs, with development of self-service booking and issue systems, integrated bibliographic databases to improve control and co-ordination between libraries, bookshops and academic staff, and experiments with electronic courseware. Likewise demand for reproduction facilities will continue, including photocopying equipment as well as downloading facilities and print stations for electronic information services and full-text document delivery systems.

There will be constant demand on enquiry services, particularly point-of-need assistance with electronic services, prompting rethinking and restructuring into tiered services, ranging from reception points, help desks and hotlines, unstaffed information points supported by hypermedia guides, in-depth research support and surgeries with appointment systems, as well as on-call technical (computing) support and comprehensive documentation. We can expect continuing reduction in mediated information searches with the trend towards end-user searching and intermediaries concentrating on complex/difficult searches and instructing or advising users on copyright and contract provisions, database selection, network access, resources available, search strategies and techniques, use of bibliographic management packages, etc. Current awareness services will become more important, with links to individual article supply, direct online access for end-users, different payment methods and new modes of network delivery (including electronic mail) and a wider choice of suppliers, including both commercial and academic community-based services in addition to the British Library. User education and instruction will shift from library orientation and use to transferable information-handling and study skills, using a variety of methods, including traditional talks, tours and workbooks, as well 
as interactive video and other computer-assisted packages, lectures and seminars integrated with teaching programmes and project assignments.

Interlibrary co-operation will continue, but there may be less emphasis on the physical transfer of materials, perhaps more travel by academics to specialist collections, and a move towards more formal partnerships on a discipline or regional basis, involving top management commitment with appropriate financial compensation for libraries providing a national service. Internally, libraries will need to develop close working relationships and form partnerships with computing, academic and administrative staff, and achieve active involvement of all customers in planning and prioritizing services, with more systematic evaluation and feedback mechanisms (such as focus groups, surveys and suggestions schemes).

\section{Management Imperatives}

Follett and Fielden highlight the critical importance of management and leadership skills for academic libraries in the electronic environment; the job of running a university library has undoubtedly become more complex, and the personal qualities and abilities required are significantly different from those associated with the traditional role of "scholar-librarian". Better investment in staff development and training will be needed to ensure a continuing supply of staff of the right calibre for the future - more comprehensive programmes covering interpersonal and communication skills, and management and business concepts and techniques, in addition to professional/technical competencies, as well as an understanding of pedagogic issues and learning styles in anticipation of Fielden's projected "para-academic" role for subject specialists working alongside academic colleagues in the learner support function. Investment of time and money must be accompanied by real commitment to continuous professional development through on-the-job learning, which implies cultural change to create libraries that are "learning organizations" in the true sense of the term as used in the literature of organizational development. Various initiatives to address these needs are in hand, such as the strategic management programme for senior library staff recently delivered by Aston Business School on behalf of SCONUL, the Universities and Colleges Staff Development Association and the Library Association, but more needs to be done to give higher priority to management development for a wider range of academic library staff.

Follett has rightly identified strategic management as an area requiring attention, stressing the need to integrate the planning of library and information services with other forms and flows of information, other teaching and learning resources, and human, physical and financial resources. More involvement of stakeholders (including customers, partners and suppliers) in library planning processes will be needed, as well as more active participation of library staff in other areas of institutional planning, notably academic programmes. Strategic planning must be followed through with marketing and business plans, and ultimately with annual operational plans and formal objectives for individual staff. A clear framework of strategic objectives and priorities, formulated through a participative planning process, will facilitate delegation of decision making and resource allocation to a level enabling quick flexible responses to identified customer needs.

Follett also pinpoints the need to clarify resource allocation mechanisms and to consider the balance of expenditure on different elements, including staff, equipment and information resources. New resource models will be needed to enable proper assessment of the relative cost-effectiveness of different modes of information provision, which take account of the differing requirements of different academic departments; it will not suffice to talk in terms of a 40:60 per 
cent split of the acquisition's budget between books and periodicals, as not only does this ignore the complementary provision of interlibrary loans and electronic sources, but it also implies an across-the-board formula for all subject disciplines. The new economic models must also include human and physical resources (staff, space, equipment, etc.) in addition to subscription, licensing and other costs of acquiring information; public access electronic information systems incur significant capital and recurrent costs, notably the costs of staff effort in supporting and training end-user searchers.

Both Follett and Fielden comment on the potential advantages of organizational restructuring to achieve more effective collaboration between library and computing staff in planning and delivering information services; Fielden also advocates more teamworking within libraries, and a less hierarchical management style. Flatter and more flexible structures will be needed, moving away from functionally-based structures to a client focus, with multi-skilled, multi-tasked teams concentrating on building relationships with their customers, anticipating their needs and offering a portfolio of services tailored to their particular requirements. Management styles must shift from the command-and-control model to facilitating, coaching and advisory roles, with day-today supervision and administration devolved to lower operational levels. Some institutions possibly the majority - will opt for converged or merged library and computing services, while others will maintain separate operations, but all will have to ensure that co-operation and teamwork becomes the norm at both strategic and operational levels, which will probably require substantial cultural change in many institutions.

\section{Conclusion}

Academic libraries face a period of continuing change which will present challenges to staff and users. Communication will be among the critical success factors for survival and success in the information society, but the ability to address the human factors - the people issues - will be even more important than the capacity to master the technology. Ultimately, it is the human element which provides the continuity enabling service developments to be planned and managed in a coherent way, as our core service values remain constant - even in the virtual library depicted by Follett. The key tasks for managers are to articulate future directions for their libraries, based on a vision shared by all stakeholders and informed by continuing environmental appraisal; to secure the financial and other resources required to achieve agreed goals; and to inspire and support colleagues as partners in an exciting collaborative venture. The information society of the twenty-first century offers the opportunity for libraries to play a central role in the academic community, but it will require bold and confident leadership along the way.

\section{References}

1. Joint Funding Councils' Libraries Review Group, Report (Chairman: Professor Sir Brian Follett), The Councils, Bristol, December 1993.

2. John Fielden Consultancy, Supporting Expansion: A Report on Human Resource Management in Academic Libraries, for the Joint Funding Councils' Libraries Review Group, The Councils, Bristol, 1993.

3. Libraries and IT, Working Papers of the Information Technology Sub-committee of the HEFCs' Libraries Review, The Office for Library and Information Networking, UKOLN, Bath, 1993. 
4. Royal Society, The British Library and Association of Professional and Learned Society Publishers, The Scientific, Technical and Medical Information System in the UK, British Library R\&D Report 6123, Royal Society, London, 1993.

5. British Library Research and Development Department and The British Academy, Information Technology in Humanities Scholarship: British Achievements, Prospects and Barriers, British Library R\&D Report 6097, Office for Humanities Communication, Oxford, 1993.

6. University Grants Committee, Report of the Committee on Libraries (Chairman: Sir Thomas Parry), HMSO, London, 1967.

7. Joint Funding Councils' Ad-hoc Group on Performance Indicators for Libraries, The Effective Academic Library: A Framework for Evaluating the Performance of UK Academic Libraries: A Consultative Report to the HEFCE, SHEFC, HEFCW and DENI... The Councils, Bristol, March 1995. 